\title{
Awareness and knowledge of Chikungunya infection following its outbreak in Pakistan among health care students and professionals: A nationwide survey
}

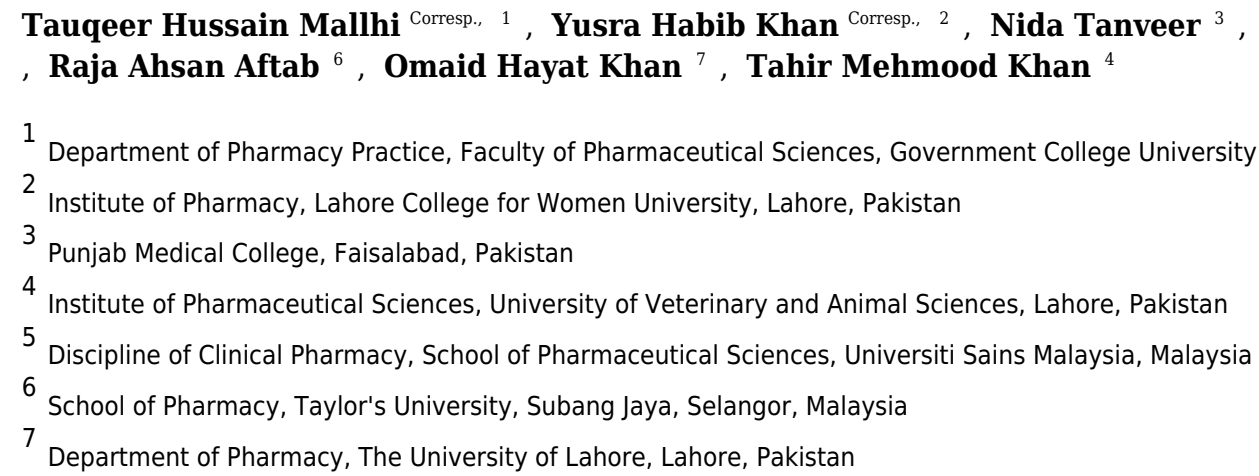

Background: The World Health Organization (WHO) declares Chikungunya (CHIK) infection to be endemic in South Asia. Despite its first outbreak in Pakistan, no documented evidence exists which reveals the knowledge or awareness of healthcare students and workers (HCSW) regarding CHIK, its spread, symptoms, treatment and prevention. Since CHIK is emergent infection in Pakistan, poor disease knowledge may result in a significant delay in diagnosis and treatment. Current study was aimed to evaluate the awareness and knowledge of CHIK among HCSW. Methods: A cross-sectional study was conducted among HCSW from teaching institutes and hospitals in seven provinces of Pakistan. We collected information on socio-demographic characteristics of the participants and their knowledge by using a 30-item questionnaire. The cumulative knowledge score (CKS) was calculated by correct answers with maximum score of 22 . The relationship between demographics and knowledge score was evaluated by using appropriate statistical methods. Results: There were 563 respondents; mean age $25.2 \pm$ 5.9 years with female preponderance (62.5\%). Of these, $319(56.7 \%)$ were aware of CHIK infection before administering the survey. The average knowledge score was $12.8 \pm 4.1$ (\% knowledge score: $58.2 \%$ ). Only $31 \%$ respondents had good disease knowledge while others had fair (36.4\%) and poor (32.6\%) knowledge. Out of five knowledge domains, domain III (vector, disease spread and transmission) and V (prevention and treatment) scored lowest among all i.e. percent score $44.5 \%$ and $54.1 \%$, respectively. We found that socio-demographic characteristics had no influence on knowledge score of the study participants. Conclusion: Approximately one-half of participants were not aware of CHIK 
infection and those who were aware, had insufficient disease knowledge. Findings of the current study underscore the dire need of educational interventions not only for health care workers but also for students, irrespective to the discipline of study. 


\section{Awareness and Knowledge of Chikungunya Infection following its outbreak}

2 in Pakistan among Health Care Students and Professionals: A Nationwide

3

4
Survey

Tauqeer Hussain Mallhi ${ }^{*}$, Yusra Habib Khan²*, Nida Tanveer ${ }^{3}$, Allah Buksh", Amer
Hayat Khan ${ }^{5}$, Raja Ahsan $\mathrm{Aftab}^{6}$, Omaid Hayat Khan ${ }^{7}$, Tahir Mehmood Khan ${ }^{4}$

${ }^{1}$ Department of Pharmacy Practice, Faculty of Pharmaceutical Sciences, Government College University Faisalabad, 38000 Faisalabad Pakistan

${ }^{2}$ Institute of Pharmacy, Lahore College for Women University, Lahore, Pakistan

${ }^{3}$ Punjab Medical College, 38000 Faisalabad, Pakistan

${ }^{4}$ Institute of Pharmaceutical Sciences, University of Veterinary and Animal Sciences, Lahore, Pakistan

${ }^{5}$ Discipline of Clinical Pharmacy, School of Pharmaceutical Sciences, Universiti Sains Malaysia, Penang 11800, Malaysia

${ }^{6}$ School of Pharmacy, Taylor`s University, 47500 Subang Jaya, Selangor, Malaysia

${ }^{7}$ Department of Pharmacy, The University of Lahore, Defense Road, Lahore, Pakistan

*Corresponding author (tauquer.hussain.mallhi@hotmail.com, yusrahabib@ymail.com) 
20 Abstract

21 Background: The World Health Organization (WHO) declares Chikungunya (CHIK) infection

22 to be endemic in South Asia. Despite its first outbreak in Pakistan, no documented evidence

23 exists which reveals the knowledge or awareness of healthcare students and workers (HCSW)

24 regarding CHIK, its spread, symptoms, treatment and prevention. Since CHIK is emergent

25 infection in Pakistan, poor disease knowledge may result in a significant delay in diagnosis and

26 treatment. Current study was aimed to evaluate the awareness and knowledge of CHIK among

27 HCSW.

28 Methods: A cross-sectional study was conducted among HCSW from teaching institutes and

29 hospitals in seven provinces of Pakistan. We collected information on socio-demographic

30 characteristics of the participants and their knowledge by using a 30-item questionnaire. The

31 cumulative knowledge score (CKS) was calculated by correct answers with maximum score of

32 22. The relationship between demographics and knowledge score was evaluated by using

33 appropriate statistical methods.

34 Results: There were 563 respondents; mean age $25.2 \pm 5.9$ years with female preponderance

35 (62.5\%). Of these, $319(56.7 \%)$ were aware of CHIK infection before administering the survey.

36 The average knowledge score was $12.8 \pm 4.1$ (\% knowledge score: $58.2 \%)$. Only $31 \%$

37 respondents had good disease knowledge while others had fair (36.4\%) and poor (32.6\%)

38 knowledge. Out of five knowledge domains, domain III (vector, disease spread and transmission)

39 and V (prevention and treatment) scored lowest among all i.e. percent score $44.5 \%$ and $54.1 \%$,

40 respectively. We found that socio-demographic characteristics had no influence on knowledge

41 score of the study participants. 
42 Conclusion: Approximately one-half of participants were not aware of CHIK infection and those

43 who were aware, had insufficient disease knowledge. Findings of the current study underscore

44 the dire need of educational interventions not only for health care workers but also for students, 45 irrespective to the discipline of study. 
46

47

48

49

50

51

52

53

55

56

57

58

59

60

61

62

63

64

65

66

67

68

\section{Introduction}

7 Chikungunya virus (CHIKV; genus Alphavirus, family Togaviridae) is transmitted to humans by Aedes mosquitos in sylvatic (animal-mosquito-man) or urban (man-mosquitoman) transmission cycle and was first identified in Tanzania in 1950s (Costa-da-Silva et al., 2017). Since its introduction to the New World, Chikungunya (CHIK) has caused impressive outbreaks in Africa, Europe, Asia, and islands of Indian and western pacific oceans (Pastula et al., 2017). According to a recent estimate, 3.6 billion people living in 124 countries are at high risk of disease with infection rates reported up to 75\% (Nasci, 2014). In summer 2017, Pakistan has experienced its first ever CHIK outbreak in Karachi, a metropolis of approximately 25 million inhabitants. This outbreak resulted in 30,000 suspected cases where only 803 were reported to World Health Organization (WHO) (Mallhi et al., 2017a). Shi et al. (2016) carried out phylogenetic analysis of CHIKV isolated from the ten patients with confirmed diagnosis and found that the epidemic of genotypes of CHIKV strains were tightly associated with spatial and temporal distributions. This analysis revealed that Pakistani strains shared high similarity and belonged to ECSA.IOL lineage. Moreover, authors found that the strains were closely related to those derived in India which suggests the possibility of their migration from India to Pakistan. Naqvi et al. (2017) evaluated clinico-laboratory spectrum of 199 isolated CHIK cases from emergency department of four tertiary care hospitals in Karachi. The most common clinical manifestations among these patients were lymphocytosis, joint pain and swelling (in small joints) followed by high grade fever $\left(>102^{\circ} \mathrm{F}\right)$, myalgia and thrombocytopenia. The duration of illness was greater than thirty days in 62 patients which was attributed to the persistent joint pain. Moreover authors also interviewed patients about the etiological factors where most of them responded mosquitos as causative agents followed 
69 by the chickens. The evidence of CHIKV in Pakistan dates back to early 1980s, when

70 Darwish et al. (1983) identified antibodies against CHIKV in sera of rodents and human.

71 Fortunately, no hospital case was reported on that occasion. Later, three children with CHIK 72 infection were identified during dengue outbreak in 2011 (Afzal et al., 2015).

The year 2016 portrayed a disturbing picture, when Pakistan has experienced a

noticeable burden of viral infections, including nineteen deaths caused by Crimean-Congo haemorrhagic fever (CCHF) and outbreaks of dengue and CHIK. The trail of viral attacks has created many concerns among health authorities and WHO (Mallhi et al., 2017b). In recent times, with an increase in global travel, the risk for spreading CHIK to non-endemic regions has heightened. Like dengue epidemics, CHIK outbreak is a result of abrupt global expression of vector-borne diseases (Charrel, Lamballerie \& Raoult, 2007). CHIK is self-limiting and has a low mortality rate; however, fatal infections and chronic rheumatic disorders do occur (Charrel, Lamballerie \& Raoult, 2007). The infection not only possess adverse impact on human health but also impedes overall socioeconomic burden of the community and health care system (Cardona-Ospina et al. 2015). The virus can establish itself in any tropical or temperate region harboring the Aedes mosquitoes. Thus, the key measures for preventing CHIK epidemics include entomologic surveillance, peridomestic mosquito control, public education, commitment of resources for research, improvements in healthcare infrastructure, detection of imported cases and early recognition of local transmission, followed by efficient vector control (Mallhi et al., 2017a, Mallhi et al., 2017b). infection, the Centers for Disease Control and Prevention (CDC) has focused on, among other things, raising awareness of both health care providers and general public (CDC, 2015). 
92 Though most intervention strategies have focused on mosquito control and mosquito bite

93 prevention but the success of these strategies relies on social factors such as knowledge and

94 awareness of diseases. Healthcare professionals (HCPs) serve as the first-line of CHIK

95 diagnosis, notification, and treatment and poor disease knowledge may result in significant

96 delay in patient's detection and management which may further associated with disease

97 spread. HCPs also play a pivotal role in providing education, increasing public awareness and

98 promoting personal protection. In this context, knowledge and awareness of disease among

99 HCPs must be appropriate and up-to-date, which could be translated into early recognition

100 and improved outcomes of CHIK control. Although WHO and CDC have embarked on a

101 CHIK awareness campaign for HCPs, the level and extent of awareness remain unknown

102 (Omodior et al., 2017). There are dearth of investigations on awareness and knowledge of

103 CHIK infection among healthcare students and workers (HCSW) in Pakistan. Furthermore, it

104 is imperative to explore knowledge of CHIK among HCSW after its outbreak in Pakistan in 105 order to evaluate their preparedness for the re-emergence of the virus. In this context, current

106 study was aimed to evaluated awareness and knowledge of CHIK infection among HCSW of 107 Pakistan. 
108 Methods

109 Ethics statement

110 Current study was approved by the Human Research Ethics Committee (HREC) at

111 Government College University Faisalabad, Pakistan (HREC/Phar/GCUF/2017-332).

112 Informed consent was obtained from all participants and data were anonymised before 113 analysis.

\section{Study site and population}

This cross-sectional study (July, 2017 to December, 2017) was conducted among

HCSW from all seven provinces or administrative states of Pakistan. We selected five major categories of health professions including pharmacists, physicians, dentists, physiotherapists and nurses. The study flow diagram is presented in Figure 1.

Figure 1: Study Flow Diagram

\section{Study Instrument}

A 30-items questionnaire comprised of three sections was developed under opinions of experts from five health professions (doctor, pharmacist, nurse, dentist, and physiotherapist). Upon completion of content validity, survey instrument was pre-tested in a small, targeted sample of HCSW $(n=30)$, with the aim of assessing the clarity and comprehensibility of questions (face validity). The reliability scale was applied for these 30 respondents and the alpha value was found at 0.811 , indicating the adequacy of the tool to

127 meet the objectives of the current study. Each section of questionnaire included close-ended 128 questions. Section I was comprised of 6 items of demographics, while Section II consisted of 2 questions evaluating the general awareness of infection. The participants, who did not hear

130 the word "chikungunya" before administering the survey were considered as "not aware of 
131 disease" and were not included in knowledge score analysis in section III. Section III was 132 comprised of 22 items which were categorized in five domains. These domains evaluated the

133 knowledge of study participants regarding CHIK infection such as; knowledge of recent 134 outbreak in Pakistan (2 items), basic disease knowledge (2 items), knowledge of vectors, 135 disease spread and transmission (6 items), symptomology (9 items), and prevention and 136 treatment of CHIK infection (3 items). The knowledge of participants was scored " 1 " for each 137 correct answer and scored " 0 " for incorrect or don't know or not sure answers. The maximum 138 cumulative knowledge score (CKS) was 22. Total percent knowledge score (Score 139 obtained/CKS $\times 100)$ was calculated for each participant and knowledge of CHIK was 140 categorized into good (score $\geq 70$ ), fair (score $50.1-69.9)$ and poor (score $\leq 50)$. The percent

141 knowledge score was also calculated against each domain of Section III. The Similar scoring 142 system has been previously adopted in several investigations (Khan et al., 2014; Khan et al., 143 2012).

\section{Data Collection}

Using convenient sampling technique, all the authors were asked to contact HCSW 146 from universities, hospitals and community health centers in each province of Pakistan for 147 interview. Authors explained the purpose of study to the target population and those who 148 agreed to participate were asked to fill the questionnaire. An informed consent was obtained 149 from each participant. Each questionnaire was collected and all the participants were educated 150 on CHIK infection, its prevention and treatments. At the end of study period, all the responses 151 were checked for completeness and data were transferred to Microsoft spreadsheet for 152 cleaning purposes.

\section{Statistical Analysis}


All the data were analyzed by SPSS version 22.0. A significance level of 0.05 was 155 used throughout. All continuous variables were reported as mean (standard deviation) or 156 median (25\%-75\% IQR), while categorical variables were described using counts (n) and 157 proportions (\%). Chi-square test or student-t test was used to compare the demographics 158 between respondents who were aware of CHIK and those who were not. Association between 159 knowledge score and socio-demographic variables was evaluated by simple linear regression 160 analysis, Pearson correlation or one-way ANOVA, where appropriate. 
161

162

163

164

165

166

167

168

169

170

171

172

173

174

175

176

177

178

179

180

181

182

\section{Results}

Out of 814, a total 618 questionnaire were received (response rate: 76\%), and 563 responses were included for the analysis after excluding 55 uncompleted forms (Figure 1). The mean age of the participants were $25.2 \pm 5.9$ years with female preponderance $(62.5 \%)$. Most of the respondents were students $(58.8 \%)$, while $36 \%$ were working professionals. About half responses were recorded from pharmacy profession, followed by doctors $(34.1 \%)$ and dentists $(8 \%)$. Four-hundred (71\%) participants were at graduation level. Being a post populated province of Pakistan, majority of the responses $(73.9 \%)$ were recorded from Punjab. Table 1 demonstrates the general demographics of the study participants and comparison of respondents who were aware of CHIK infection with those who were not.

Alarmingly, $244(43.3 \%)$ respondents had never heard about CHIK infection before administering the survey, while 319 (56.7\%) participants stated that they were aware of the disease. Among respondents who were aware, the primary source of information was television $(33.5 \%)$ followed by social networks $(25.08 \%)$ and newspaper (15.05\%) (Figure 2). The association of awareness with demographics was evaluated using Chi-square statistics (Table 1). The respondents with age $26-39$ years had CHIK awareness $(p=0.001)$, while those of $18-25$ years were unaware of disease $(p=0.001)$. Gender had no impact on disease awareness in the present study. Health students were significantly $(p=0.002)$ associated with unawareness of disease, while health professionals were aware of CHIK $(p=0.001)$. Among health professions included in the current study, pharmacy and MBBS were associated with disease awareness, while all other professions were statistically associated with unawareness. Only the respondents from Sindh province had significant awareness of CHIK Infection. 
184 Figure 2: Sources of Information of Chikungunya Infection among study participants $(\mathrm{n}=319)$

185 The mean cumulative knowledge score (CKS) was $12.8 \pm 4.1$ (Median: 14, range" $0-21$, 186 percent knowledge score: $58.2 \%$ ). The proportion of participants with good knowledge was $31 \%$, 187 while $36.4 \%$ and $32.6 \%$ respondents were having fair and poor knowledge of CHIK, 188 respectively. The least scored (44.5\%) domain was "knowledge of vector, disease spread and 189 transmission" followed by the domain "Knowledge of prevention and treatment" (54.1\%). 190 However, the basic disease knowledge of the respondents was good (\% score: $71.8 \%$ ). The 191 percentage score ranged from fair to poor in all other domains assessing the knowledge among 192 participants. Table 2 demonstrates questions evaluating the knowledge of participants with 193 average knowledge score of each item and \% knowledge score of each domain. 

196 relationship of demographic parameters with knowledge score. Though the knowledge score 197 was higher in age 26 - 39 years, working professionals, MBBS field of education and Sindh 198 province but statistical significant association was not present as compared to others (Table $1993)$.

Table 3

201 The relationship between demographics and CKS was further assessed with simple linear 202 regression (Table 4). Though demographics made contribution to explaining the dependent 203 variable (i.e CKS), but the association was statistically insignificant. 


\section{Discussion}

To the best of our knowledge, this is the first nationwide study to explore the awareness and extent of knowledge about basics, spread, transmission, symptoms, prevention and treatment of CHIK infection among healthcare students and workers (HCSW) after its outbreak in Pakistan. Previous closely related investigations conducted in Pakistan either included very few participants or limited to HCSW from one or two cities (Gul, Aziz \& Tarik, 2014; Mansoor et al., 2017).

The main findings of the present study revealed that HCSW had inadequate awareness and knowledge of CHIK infection. It is pertinent to mention that approximately half of the study participants did not hear the word "chikungunya" before administering the survey. Another recent investigation in Pakistan reported that $18.8 \%$ of healthcare professionals had never heard of the disease (Mansoor et al., 2017). The level of awareness reported by Mansoor et al. (2017) was higher as compared to our findings, which might be attributed to the inclusion of only physicians and study location, as all the study participants were belonged to well-equipped and reputed hospitals located in the capital of Pakistan. Authors have also described that CHIK infection is not an important part of syllabus of physicians. Being HCSW, provision of adequate information and education to the public is an ethical obligation. However, to carry out such services, their disease knowledge must be sufficient and up-to-date. Clinical and epidemiological similarities with dengue fever make CHIK diagnosis difficult, which may lead physicians to misdiagnose CHIK as dengue fever, particularly in parts of world where awareness of CHIK is scarce. Pakistan is one of such country in which CHIK outbreak was initially reported as "mysterious disease" (Dunya, 2016) and it might be attributed to the inadequate awareness of disease among healthcare professionals. A previous survey conducted on HCSW in Pakistan 
228 indicated that about $25 \%$ of study population had very little information of CHIK (Gul, Aziz \&

229 Tarik, 2014). Lack of awareness in large proportion of HCSW in the present study is alarming.

230 Health and teaching institutes should arrange talk or awareness programs immediately after

231 reporting of disease epidemic, in order to ensure effective preparedness for future events. Our

232 findings indicate that healthcare students from pharmacy, dentistry, physiotherapy and nursing,

233 who were at graduation level of education from all provinces, except Sindh, were associated with

234 unawareness of disease. However, the awareness was comparatively higher among working

235 professionals, especially in Sindh Province. It might be attributed to the reason that first CHIK

236 epidemic was occurred in Sindh province of Pakistan. Most of the study participants reported

237 that they had heard about CHIK through television or electronic media. Similar findings have

238 been indicated by Mansoor et al. (2017) where 43\% physicians reported electronic media as a

239 primary source of disease awareness. In addition to the electronic media and social networks,

240 health authorities must ensure disease awareness campaigns in hospitals and health teaching 241 institutes.

Knowledge scoring was done among participants who were aware of chikungunya $(\mathrm{N}=$

243 319) by excluding the respondents who had never heard about the disease. Though electronic

244 media played pivotal role in highlighting the emergence of disease in Pakistan (Dunya, 2016) but

245 still one fourth of the participants had no knowledge of recent outbreak of CHIK in the country.

246 Approximately, 77\% respondents were aware of etiological cause of disease and these findings

247 are consistent with the results of previous investigation (Mansoor et al., 2017). In contrast, Gul,

248 Aziz \& Tarik, (2014) reported that only 22\% healthcare professionals were aware of the disease

249 cause. It is important to mention that knowledge score regarding disease vector, spread and

250 transmission was lowest among all domains. This domain describes the vector control measures 
251 along with disease teratogenicity and such low score depicts that HCSW are not well prepared to

252 educate the general public. These findings instigate the dire need of disease education, especially

253 emergent infectious diseases, among HCSW.

254 The average score of symptomology domain was fair $(64.5 \%)$ in the current study and is 255 comparable with the study conducted in Pakistan where 65.5\% participants reported correct 256 symptoms of CHIK (Mansoor et al., 2017). In another study investigating the knowledge of 257 CHIK among HCSW in Colombia reported that 92\% respondents correctly reported the 258 symptoms of disease (Bedoya-Arias et al., 2015). Fever was answered as frequent presentation of 259 CHIK while nausea and rash were least scored by the participants in the present study. Since 260 CHIK shares common symptoms with dengue and Zika, appropriate knowledge on disease 261 presentations is a cardinal feature to distinguish these closely related infectious diseases and to 262 ensure the correct and timely diagnosis. Accurate knowledge of disease manifestations is 263 mainstay of referral or successful therapy. Clinical and epidemiological similarities with dengue 264 fever make CHIK diagnosis difficult, which may lead physicians to misdiagnose CHIK as

265 dengue fever; therefore, the incidence of CHIK may actually be higher than currently believed 266 (Thiboutot et al., 2010). We urge regulatory authorities to ensure the continuous medical 267 education (CME) for health professionals, specifically for diseases requiring differential or 268 distinctive diagnoses.

Currently, CHIK is treated symptomatically, usually with non-steroidal anti270 inflammatory drugs or steroids, bed rest, and fluids (Thiboutot et al., 2010). Alarmingly, more 271 than half of the study participants were not aware of CHIK treatment, where $38 \%$ respondents 272 reported that they were not sure whether any specific medication is available for its treatment. 273 Despite the gravity of its infectious potency and the fear of it being a potential biological 
274 weapon, there is currently no vaccine for CHIK infections. Only 34\% HCSW responded that

275 there is no commercial vaccine for CHIK while $12 \%$ agreed to its availability and $38 \%$ were not

276 sure. Low knowledge score of prevention and treatment domain among HCSW warrants the

277 earnest maneuvers by the health authorities. The relationship between demographics and

278 knowledge score was evaluated among studied participants with no influence of demographic

279 characteristics on knowledge scoring. These findings insist the need of health professional

280 education initiatives for epidemic diseases throughout all disciplines of health care system.

A crucial element in vector-borne diseases is behavioral change. WHO works with

282

283

284

285

286

287

288

289

290

291

292

293

294

partners to provide education and improve awareness so that people know how to protect themselves and their communities from mosquitoes, ticks, bugs, flies and other vectors (WHO Fact Sheet, 387). An effective public health education can only be possible with appropriate disease knowledge among HCSW. To ensure all graduating health professionals are prepared to engage in public health activities, education in this field must be provided during their main years of education (Law et al., 2017). Public health education should be incorporated into the curricula of health professional studies within developing nations so all graduates are prepared to engage in public health activities.

Performing studies focused on quantifying and reinforcing knowledge among HCSW in regions with high prevalence of CHIK is important for disease outbreak preparedness. Knowledge about the vector involved in its transmission plays an important role in disease prevention. Finally, symptomatology recognition by the community leads to timely admission to health centers for optimal disease management. (Bedoya-Arias et al., 2015). 
296 the sample and cannot be generalized to the broader context. However, the findings can be

297 implicated to all four provinces of Pakistan to initiate targeted measures. It is quite possible that

298 the segment of the population not represented in the study (senior skilled professionals who

299 refused to participate due to their busy schedule) is significantly different in some respect.

300 Moreover, the participation from small administrative states including FATA, GB and AJK was

301 limited which precludes the implications of the findings in these states. The proportion of

302 responses from dentists, physiotherapists and nurses was comparatively less which may bias the

303 findings towards physicians and pharmacists and underscore the consideration of equal response

304 proportion for future studies. The knowledge evaluation in this study was based on very basic

305 questions and there is high propensity that detailed knowledge analysis may yield poor scores

306 among participants. Nevertheless, current study is strengthened by the first nationwide survey

307 including large pool of HCSW from various disciplines and evaluates the extent of knowledge

308 and their relationship with demographic profile. The findings of the present study will serve to

309 design and implement disease knowledge initiatives by the health authorities in the existing 310 vector control programs.

\section{Conclusions}

The awareness and knowledge of CHIK infection among healthcare students and workers are insufficient to meet the standards of preparedness for future outbreak events. Since Pakistan

314 is experiencing the quadruple burden of vector borne diseases (VBDs), adequate information on

315 these diseases among HCSW and their effective provision to the general community is essential

316 to quell the growing risks of disease spillover. Our findings underscore the need of

317 multidimensional approaches to educate HCSW for emerging VBDs. More comprehensive and 
318 elaborated nationwide surveys are needed to strategize the targeted education plan for health 319 professionals. 
320

321

322

323

324

325

326

327

328

329

330

331

332

333

334

335

336

337

338

\section{References}

Afzal MF, Naqvi SQ, Sultan MA, Hanif A. Chikungunya fever among children presenting with nonspecific febrile illness during an epidemic of dengue fever in Lahore, Pakistan. Merit Res J Med Med Sci. 2015; 3(3): 69-73.

Bedoya-Arias JE, Murillo-García DR, Bolaños-Muñoz E, Hurtado-Hurtado N, Ramírez-Jaramillo V, Granados-Álvarez S, Rodríguez-Morales AJ. Healthcare students and workers' knowledge about epidemiology and symptoms of chikungunya fever in two cities of Colombia. The Journal of Infection in Developing Countries. 2015 Mar 15; 9(03): 330-2.

\section{Cardona-Ospina JA, Villamil-Gómez WE, Jimenez-Canizales CE, Castañeda-} Hernández DM, Rodríguez-Morales AJ. Estimating the burden of disease and the economic cost attributable to chikungunya, Colombia, 2014. Transactions of The Royal Society of Tropical Medicine and Hygiene. 2015 Dec 1; 109(12): 793-802.

Charrel RN, de Lamballerie X, Raoult D. Chikungunya outbreaks-the globalization of vectorborne diseases. New England Journal of Medicine. 2007; 356(8): 769.

\section{Costa-da-Silva AL, Ioshino RS, Petersen V, Lima AF, dos Passos Cunha M, Wiley} MR, Ladner JT, Prieto K, Palacios G, Costa DD, Suesdek L. First report of naturally infected Aedes aegypti with chikungunya virus genotype ECSA in the Americas. PLoS neglected tropical diseases. 2017; 14, 11(6): e0005630. 

survey for certain arboviruses (Togaviridae) in Pakistan. Transactions of the Royal Society of Tropical Medicine and Hygiene. 1983; 77(4): 442-5.

Dunya News. Mysterious disease affects 30,000 people in Karachi 2016. Available at http://dunyanews.tv/en/Pakistan/366034-Mysterious-disease-affects-30000-people-in-Karach (Accessed 14 March 2017)..

Gul S, Aziz S, Tarik S. "Chikungunya- The Need for Instigating Awareness in Pakistan" Int J for pharm Res Sch. 2014; 12(3): 2277-7873.

Khan YH, Sarriff A, Khan AH, Mallhi TH. Knowledge, attitude and practice (KAP) survey of osteoporosis among students of a tertiary institution in Malaysia. Tropical Journal of Pharmaceutical Research. 2014; 13(1): 155-62.

Khan YH, Sarriff A, Khan AH. A Review of Knowledge, Attitude and Practices (KAP) Of Community Population towards Osteoporosis. Journal of Applied Pharmacy. 2012; $4(3)$.

Law MG, Maposa P, Steeb DR, Duncan G. Addressing the global need for public health clinical pharmacists through student pharmacist education: a focus on developing nations. International journal of clinical pharmacy. 2017 Dec 1; 39(6): 1141-4. outbreak of Chikungunya in Pakistan. Frontiers in public health. 2017a Sep 28; 5:261. 

Pakistan: a trail of viral attacks. New Microbes New Infect. 2017b; 19: 13-4. Knowledge of Chikungunya Fever among the Postgraduate Trainees, Medical Officers and Private General Practitioners of Islamabad, Rawalpindi and Wah. Ann. Pak. Inst.

Naqvi S, Bashir S, Rupareliya C, Shams A, Giyanwani PR, Ali Z, Qamar F, Kumar

V, Talib V. Clinical spectrum of chikungunya in Pakistan. Cureus. 2017 Jul;9(7).

Nasci RS. Movement of chikungunya virus into the Western hemisphere. Emerging infectious diseases. 2014 Aug; 20(8): 1394. awareness among US travelers to caribbean destinations. International Journal of Travel Medicine and Global Health. 2017; 5(1): 20-7. TH, Staples JE, Fischer M, Hills SL. Chikungunya virus disease outbreak in Yap State, Federated States of Micronesia. PLoS neglected tropical diseases. 2017; 11(3): e0005410. origination of CHIKV epidemics in Pakistan in 2016. Virologica Sinica. 2017 Dec 1;32(6):520-32. 
379 Srikanth P, Weiner DB, Muthumani K. Chikungunya: a potentially emerging 380 epidemic?. PLoS neglected tropical diseases. 2010 Apr 27; 4(4): e623.

381 CDC. US Centers for Disease Control \& Prevention. Chikungunya Information for Vector

382 Control Programs. Available at

383 https://www.cdc.gov/chikungunya/pdfs/CHIKV_VectorControl.pdf (accessed 21 May 2018)

384 WHO. World Health Organization Fact Sheet 387. Available at 385 http://www.who.int/mediacentre/factsheets/fs387/en/. 


\section{Table 1 (on next page)}

Demographics of study Participants and their association with chikungunya awareness 
1 Table 1: Demographics of study Participants and their association with chikungunya awareness

\begin{tabular}{|c|c|c|c|c|}
\hline & $\begin{array}{c}\text { Total } \\
\text { Participants } \\
\mathbf{N}=\mathbf{5 6 3}\end{array}$ & $\begin{array}{c}\text { Participants who } \\
\text { were not aware of } \\
\text { CHIK } \\
\text { (unawareness) } \\
\mathrm{N}=244 \\
\end{array}$ & $\begin{array}{c}\text { Participants who } \\
\text { were aware of } \\
\text { CHIK } \\
\text { (awareness) } \\
\mathbf{N}=\mathbf{3 1 9} \\
\end{array}$ & $\begin{array}{c}\mathbf{P} * \\
\text { value }\end{array}$ \\
\hline Age (years) & $25.2 \pm 5.9$ & $24.7 \pm 7.1$ & $25.6 \pm 4.9$ & 0.066 \\
\hline $18-25$ Years & $375(66.6 \%)$ & $181(74.2 \%)$ & $194(60.8 \%)$ & 0.001 \\
\hline $26-39$ Years & $174(30.9 \%)$ & $57(23.4 \%)$ & $117(36.7 \%)$ & 0.001 \\
\hline$\geq 40$ Years & $14(2.5 \%)$ & $6(2.5 \%)$ & $8(2.5 \%)$ & 0.971 \\
\hline Gender & & & & 0.799 \\
\hline Male & $211(37.5 \%)$ & $90(36.9 \%)$ & $121(37.9 \%)$ & \\
\hline Female & $352(62.5 \%)$ & $154(63.1 \%)$ & $198(62.1 \%)$ & \\
\hline \multicolumn{5}{|l|}{ Working Status } \\
\hline Student & $331(58.8 \%)$ & $161(66 \%)$ & $170(53.3 \%)$ & 0.002 \\
\hline Working & $205(36.4 \%)$ & $69(28.3 \%)$ & $136(42.6 \%)$ & 0.001 \\
\hline Unemployed & $27(4.8 \%)$ & $14(5.7 \%)$ & $13(4.1 \%)$ & 0.360 \\
\hline Field of Education & & & & 0.002 \\
\hline Pharmacy & $282(50.1 \%)$ & $103(42.2 \%)$ & $179(56.1 \%)$ & 0.001 \\
\hline MBBS & $192(34.1 \%)$ & $77(31.6 \%)$ & $115(36.1 \%)$ & 0.265 \\
\hline BDS & $45(8 \%)$ & $31(12.7 \%)$ & $14(4.4 \%)$ & $<0.001$ \\
\hline Physiotherapy & $19(3.4 \%)$ & $14(5.7 \%)$ & $5(1.6 \%)$ & 0.007 \\
\hline Nursing & $25(4.4 \%)$ & $19(7.8 \%)$ & $6(1.9 \%)$ & 0.001 \\
\hline Level of Education & & & & 0.003 \\
\hline Graduation & $400(71 \%)$ & $189(77.5 \%)$ & $211(66.1)$ & \\
\hline Post-graduation & $163(29 \%)$ & $55(22.5 \%)$ & $108(33.9)$ & \\
\hline Provinces & & & & $<0.001$ \\
\hline Punjab & $416(73.9 \%)$ & $187(76.6 \%)$ & $229(71.8 \%)$ & 0.191 \\
\hline Sindh & $39(6.9 \%)$ & $3(1.2 \%)$ & $36(11.3 \%)$ & $<0.001$ \\
\hline Balochistan & $14(2.5 \%)$ & $7(2.9 \%)$ & $7(2.2 \%)$ & 0.611 \\
\hline Khyber Pakhtunkhwa (KPK) & $73(13 \%)$ & $34(13.9 \%)$ & $39(12.2 \%)$ & 0.550 \\
\hline $\begin{array}{l}\text { Federally Administered } \\
\text { tribal areas (FATA) }\end{array}$ & $13(2.3 \%)$ & $8(3.3 \%)$ & $5(1.6 \%)$ & 0.180 \\
\hline Gilgit Baltistan (GB) & $3(0.5 \%)$ & $1(0.4 \%)$ & $2(0.6 \%)$ & 0.726 \\
\hline $\begin{array}{l}\text { Azad Jammu \& Kashmir } \\
(\text { AJK) }\end{array}$ & $5(0.9 \%)$ & $4(1.6 \%)$ & $1(0.3 \%)$ & 0.97 \\
\hline $\begin{array}{l}\text { MBBS: Bachelor of Medicine, Bac } \\
\text { *P values represents the difference } \\
\text { by Chi-square Test or Fischer Exac }\end{array}$ & $\begin{array}{l}\mathrm{r} \text { of Surgery, } \\
\text { emographics } 1 \\
\text { st for categori }\end{array}$ & $\begin{array}{l}\text { : Bachelor of Dental } \\
\text { veen awareness and u } \\
\text { variables and student- }\end{array}$ & $\begin{array}{l}\text { ry } \\
\text { eness of chikı } \\
\text { for continuous }\end{array}$ & $\begin{array}{l}\text { alculate } \\
\text { age) }\end{array}$ \\
\hline
\end{tabular}




\section{Table 2 (on next page)}

Knowledge questions and their responses by the participants with average knowledge score (AKS) of each item 
1 Table 2: Knowledge questions and their responses by the participants with average knowledge

2 score (AKS) of each item

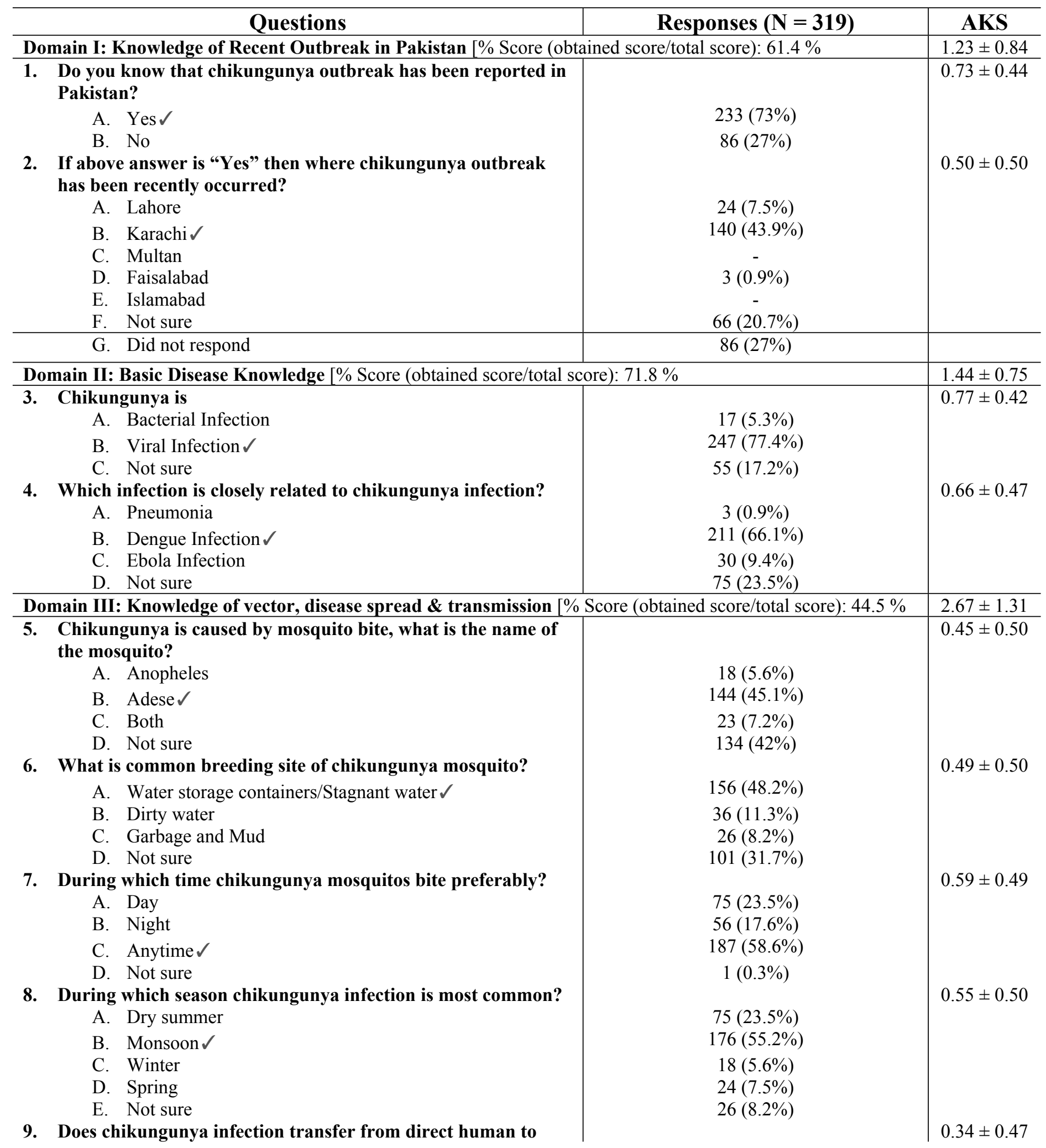


human contact?
A. Yes
B. No $\sqrt{ }$
C. Not Sure

10. Does chikungunya infection transfer from mother to new born child?
A. Yes $\checkmark$
B. No
C. Not sure

infection transfer from mother to new born

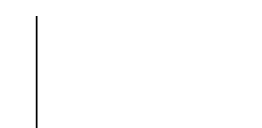

\author{
$69(21.6 \%)$ \\ $108(33.9 \%)$ \\ $142(44.5 \%)$
}

$0.25 \pm 0.43$

Domain IV: Symptomology [\% Score (obt
11. Is fever a symptom of chikungunya?

A. Yes $\sqrt{ }$

B. No

C. Not sure

12. Is joint pain a symptom of chikungunya?

$\begin{array}{ll}\text { A. } & \text { Yes } \checkmark \\ \text { B. No } \\ \text { C. Not sure }\end{array}$

13. Is muscle pain a symptom of chikungunya?
A. Yes $\checkmark$
B. No
C. Not sure

14. Is headache a symptom of chikungunya?
A. Yes $\sqrt{ }$
B. No
C. Not sure

15. Is nausea a symptom of chikungunya?
A. Yes $\sqrt{ }$
B. No
C. Not sure

16. Is fatigue a symptom of chikungunya?
A. Yes $\sqrt{ }$
B. No
C. Not sure

17. Is fever a symptom of chikungunya?
A. Yes $\sqrt{ }$
B. No
C. Not sure

18. After the bite of infected mosquito, how many days it take to appear symptoms?
A. Abruptly (immediately after bite)
B. 3-7 days $\sqrt{ }$
C. on next day of mosquito bite
D. Not sure

19. For how many days symptoms of chikungunya last?
A. One month
B. 7-10 days $\checkmark$
C. One day
D. Not sure

\begin{tabular}{|l|l|} 
& \\
& \\
& \\
& \\
\hline
\end{tabular}

$5 \%$

$$
81(25.4 \%)
$$$$
53(16.6 \%)
$$$$
185(58 \%)
$$

\begin{tabular}{|c|c|} 
& \\
$283(0.6 \%)$ & \\
\hline $2(88.7 \%)$ & \\
\hline $34(10.7 \%)$ & \\
& 0. \\
\hline
\end{tabular}

$247(77.4 \%)$

$11(3.4 \%)$

$61(19.1 \%)$

\begin{tabular}{|c|c|} 
& \\
$231(72.4 \%)$ & 0.7 \\
$7(2.2 \%)$ & \\
$81(25.4 \%)$ & \\
\hline
\end{tabular}

$0.72 \pm 0.45$

\begin{tabular}{|l|}
\hline \\
\hline
\end{tabular}

|

\begin{tabular}{|c|c|} 
& 0.7 \\
\hline $11(3.5 \%)$ & \\
$80(25.1 \%)$ & \\
\hline & 0.4
\end{tabular}

$0.71 \pm 0.45$

\begin{tabular}{|c|c} 
& $0.48 \pm 0.50$ \\
\hline $375(48.3 \%)$ & \\
\hline $128(40.1 \%)$ & \\
\hline $238(74.6 \%)$ & $0.75 \pm 0.44$ \\
\hline $13(4.1 \%)$ & \\
\hline
\end{tabular}

\begin{tabular}{l}
\hline \\
\hline
\end{tabular}

68

$13(4.1 \%)$

$68(21.3 \%)$

\begin{tabular}{|c|c} 
& $0.56 \pm 0.50$ \\
\hline $28(8.8 \%)$ & \\
\hline $112(35.1 \%)$ & \\
\hline & $0.54 \pm 0.50$
\end{tabular}

Domain V: Prevention and Treatment [\% Score (obtained score/total score): $54.1 \%$

20. Is Chikungunya preventable disease?

$$
\begin{gathered}
11(3.4 \%) \\
173(54.2 \%) \\
11(3.4 \%) \\
124(38.9 \%) \\
48(15 \%) \\
120(37.6 \%) \\
2(0.6 \%) \\
49(46.7 \%)
\end{gathered}
$$



A. Yes $\checkmark$
B. No
C. Not Sure

21. Is there any specific drug available for chikungunya treatment?

A. Yes

B. No $\sqrt{ }$

C. Not sure

22. Is there any vaccine available for chikungunya prevention?
A. Yes
B. No $\sqrt{ }$
C. Not Sure

\begin{tabular}{l|l}
$249(78.1 \%)$ & \\
$12(3.8 \%)$ & $0.50 \pm 0.50$ \\
$58(18.2 \%)$ & \\
& \\
$38(11.9 \%)$ & \\
$159(49.8 \%)$ & \\
$122(38.2 \%)$ & \\
$61(19.1 \%)$ & \\
$110(34.5 \%)$ & \\
$148(46.4 \%)$ & \\
\hline
\end{tabular}

$249(78.1 \%)$

$12(3.8 \%)$

$58(18.2 \%)$

$38(11.9 \%)$

$159(49.8 \%)$

$122(38.2 \%)$

$61(19.1 \%)$

$148(46.4 \%)$

$\checkmark$ Represents the correct answer

AKS: average knowledge score with standard deviation

3 


\section{Table 3 (on next page)}

Distribution of knowledge score among demographics of study participants 
1 Table 3: Distribution of knowledge score among demographics of study participants

\begin{tabular}{|c|c|c|c|}
\hline & $\begin{array}{c}\text { Respondents } \\
\mathbf{N}=319\end{array}$ & $\begin{array}{c}\text { Knowledge } \\
\text { Score (out of 22) }\end{array}$ & $P *$ value \\
\hline Age (years) & $25.6 \pm 4.9$ & & $\mathrm{r}: 0.06(\mathrm{P}=0.274)^{1}$ \\
\hline Age Categories & & & $0.798^{2}$ \\
\hline $18-25$ Years & $194(60.8 \%)$ & $12.7 \pm 4.4$ & \\
\hline $26-39$ Years & $117(36.7 \%)$ & $13.0 \pm 5.0$ & \\
\hline$\geq 40$ Years & $8(2.5 \%)$ & $12.4 \pm 6.0$ & \\
\hline Gender & & & $0.709^{3}$ \\
\hline Male & $121(37.9 \%)$ & $12.9 \pm 4.7$ & \\
\hline Female & $198(62.1 \%)$ & $12.7 \pm 4.7$ & \\
\hline Working Status & & & $0.104^{2}$ \\
\hline Student & $170(53.3 \%)$ & $12.4 \pm 4.7$ & \\
\hline Working & $136(42.6 \%)$ & $13.4 \pm 4.4$ & \\
\hline Unemployed & $13(4.1 \%)$ & $11.3 \pm 6.3$ & \\
\hline Field of Education & & & $0.486^{2}$ \\
\hline Pharmacy & $179(56.1 \%)$ & $12.7 \pm 4.8$ & \\
\hline MBBS & $115(36.1 \%)$ & $13.1 \pm 4.6$ & \\
\hline BDS & $14(4.4 \%)$ & $12.6 \pm 3.2$ & \\
\hline Physiotherapy & $5(1.6 \%)$ & $9.2 \pm 5.5$ & \\
\hline Nursing & $6(1.9 \%)$ & $12.2 \pm 3.1$ & \\
\hline Level of Education & & & $0.924^{3}$ \\
\hline Graduation & $211(66.1 \%)$ & $12.8 \pm 4.4$ & \\
\hline Post-graduation & $108(33.5 \%)$ & $12.7 \pm 5.1$ & \\
\hline Provinces & & & $0.648^{2}$ \\
\hline Punjab & $229(71.8 \%)$ & $12.8 \pm 4.8$ & \\
\hline Sindh & $36(11.3 \%)$ & $13.6 \pm 3.4$ & \\
\hline Balochistan & $7(2.2 \%)$ & $10.6 \pm 5.5$ & \\
\hline Khyber Pakhtunkhwa (KPK) & $39(12.2 \%)$ & $12.3 \pm 4.7$ & \\
\hline Federally Administered tribal areas (FATA) & $5(1.6 \%)$ & $10.8 \pm 2.1$ & \\
\hline Gilgit Baltistan (GB) & $2(0.6 \%)$ & $14.5 \pm 2.1$ & \\
\hline Azad Jammu \& Kashmir (AJK) & $1(0.3 \%)$ & 12.0 & \\
\hline
\end{tabular}

${ }^{1}$ Pearson Correlation, ${ }^{2}$ One-Way ANOVA, ${ }^{3}$ Student t-test

2 
Table 4 (on next page)

Simple linear regression analysis examining the contribution of demographics to cumulative knowledge score (CKS) 
1 Table 4: Simple linear regression analysis examining the contribution of demographics to

2 cumulative knowledge score (CKS)

\begin{tabular}{|c|c|c|c|c|c|}
\hline \multirow{2}{*}{ Variables } & \multicolumn{2}{|c|}{ Beta } & \multirow{2}{*}{ Sig. } & \multicolumn{2}{|c|}{$\begin{array}{l}\text { 95\% Confidence } \\
\text { Interval }\end{array}$} \\
\hline & Unstandardized & Standardized & & $\begin{array}{l}\text { Lower } \\
\text { Bound }\end{array}$ & $\begin{array}{l}\text { Upper } \\
\text { Bound }\end{array}$ \\
\hline Age & 0.303 & 0.032 & 0.571 & 0.748 & 1.353 \\
\hline Gender & -0.201 & -0.021 & 0.709 & -1.257 & 0.856 \\
\hline Working status & 0.090 & 0.101 & 0.172 & 0.939 & 1.119 \\
\hline $\begin{array}{l}\text { Field of } \\
\text { education }\end{array}$ & -0.417 & -0.043 & 0.442 & -1.484 & 0.657 \\
\hline $\begin{array}{l}\text { Level of } \\
\text { Education }\end{array}$ & -0.055 & -0.006 & 0.920 & -1.139 & 1.028 \\
\hline Provinces & -0.919 & -0.063 & 0.265 & -2.337 & 0.699 \\
\hline \multicolumn{6}{|c|}{$\begin{array}{l}\text { Simple linear correlation (dependent variable: cumulative knowledge score, independent } \\
\text { variables: binary demographic variables) } \\
\text { Reference (constant): age ( } \leq 25 \text { years), gender (male), working status (student), field of } \\
\text { education (MBBS), level of education (graduation), provinces (Sindh) }\end{array}$} \\
\hline
\end{tabular}

3 
Figure 1

Study Flow Diagram

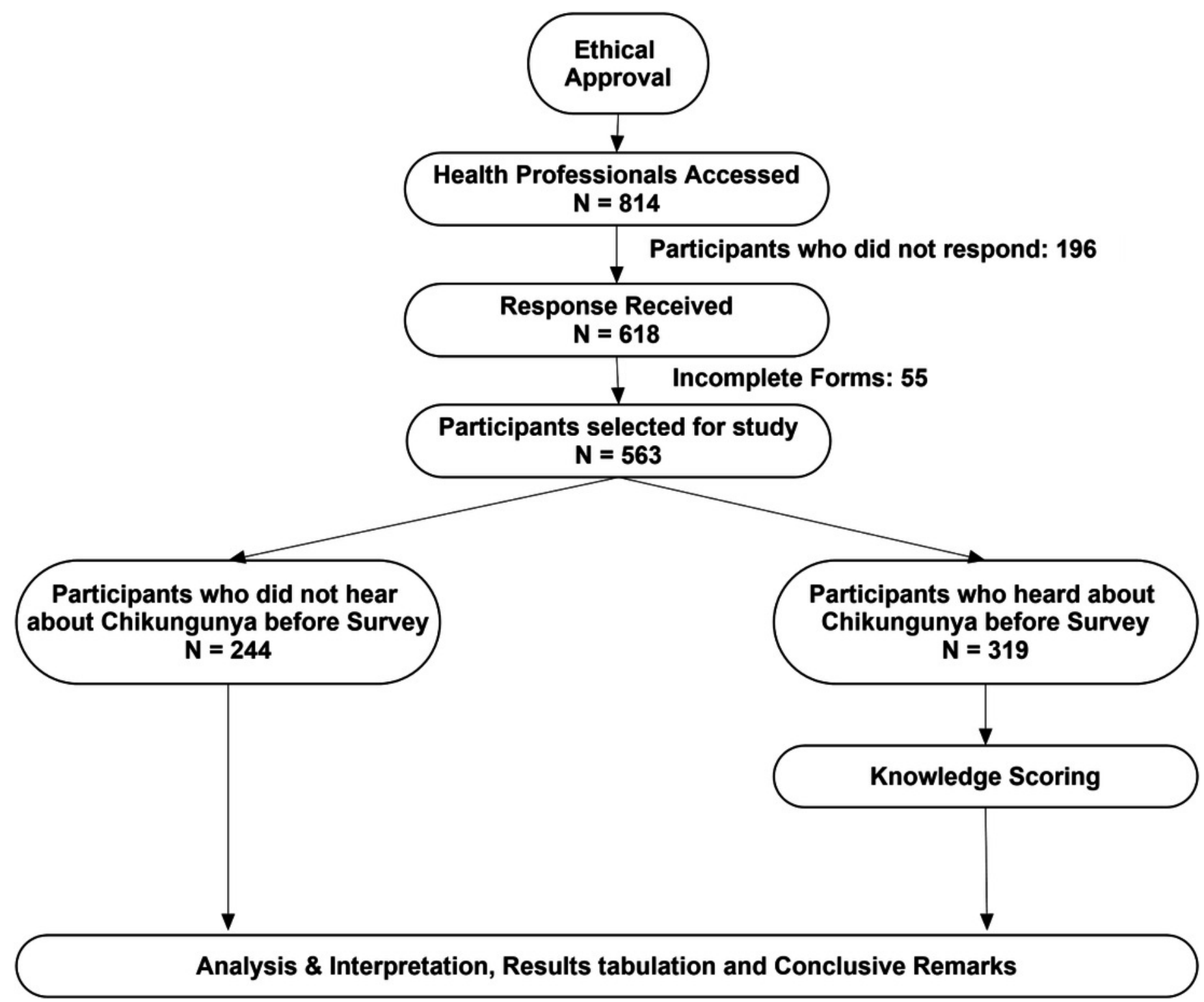


Figure 2

Sources of Information of Chikungunya Infection among study participants $(n=319)$

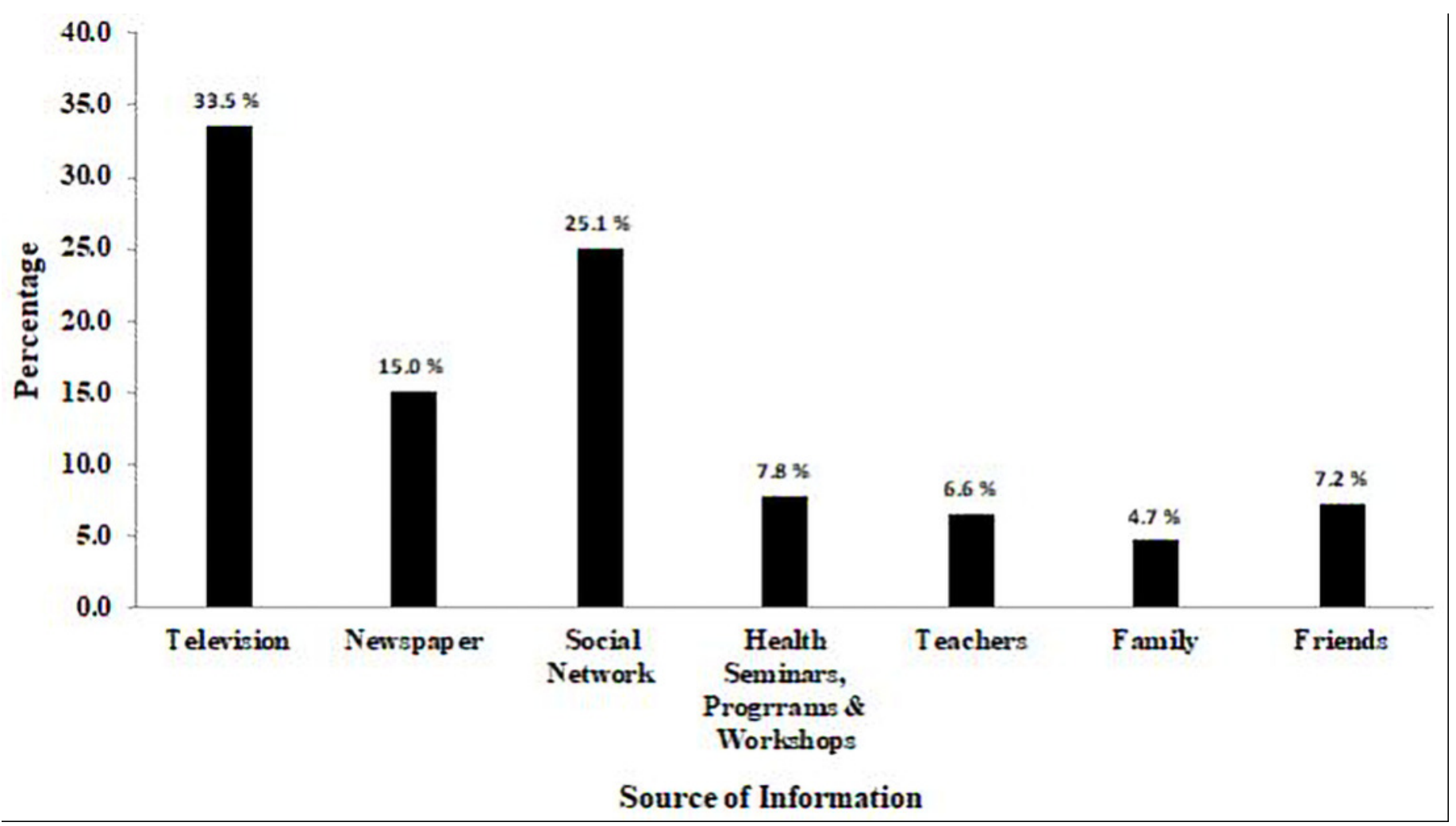

